\title{
Changes in corneal properties and its effect on intraocular pressure measurement following phacoemulsification with intraocular lens implantation with or without trabeculectomy
}

\author{
Ashim Dey ${ }^{1,2,3}$, Rathini Lilian David ${ }^{3}$, Rashima Asokan ${ }^{1,2,3}$, Ronnie \\ George 3 \\ 'Elite School of Optometry, Chennai, India; ${ }^{2 B i r l a}$ Institute of Technology and \\ Science, Pilani, India; ${ }^{3}$ Medical and Vision Research Foundation, Chennai, India
}

\begin{abstract}
Purpose: To evaluate the changes in corneal biomechanical properties and their effect on pre-and postoperative differences in IOP measurement by each tonometer.

Design: Observational study.

Methods: The study was done in subjects who underwent phacoemulsification with intraocular lens (IOL) implantation (phaco-IOL) and combined phacoemulsification with $I O L$ implantation and trabeculectomy (phaco-trab). IOP was measured by a single trained examiner using rebound tonometer (RBT), Ocular Response Analyzer (ORA), Goldmann applanation tonometer (GAT), dynamic contour tonometer (DCT), and Tono-Pen. Corneal hysteresis $(\mathrm{CH})$ and corneal resistance factor (CRF) were measured using ORA, central corneal thickness (CCT) using ultrasonic pachymeter, and corneal curvature $(C R)$ with manual keratometry. All measurements were done one week prior to surgery and after four weeks and six weeks of the two surgeries respectively. Only the operated eye was included for analysis.

Results: Twenty-nine eyes of 29 normal subjects who underwent phaco-IOL and 23 eyes of 23 glaucoma subjects who underwent phaco-trab were studied. Increase in CCT [10.2 \pm 14.86 microns, $p=0.001]$, decrease in $\mathrm{CH}[0.82 \pm 1.38 \mathrm{mmHg}, p=0.003]$ and CRF [0.97 \pm $1.0 \mathrm{mmHg}, p<0.001]$ were found post-phaco-IOL, whereas post-phaco-trab decrease in CCT [16.61 \pm 15.22 microns, $p<0.001]$, CRF [2.28 $\pm 1.93 \mathrm{mmHg}, p<0.001]$ with increase in $\mathrm{CH}[0.95 \pm 1.89 \mathrm{mmHg}, p=0.03]$ were noted. Multiple linear regression analysis showed significant associations for change in $\mathrm{CH}$ and CRF with change in IOP and not with CCT and CR postoperatively.

Conclusion: Alterations in $\mathrm{CH}$ and $\mathrm{CRF}$ were associated with changes in IOP measured postoperatively by different tonometers. $\mathrm{CH}$ and CRF changes contribute to postoperative changes in measured IOP.
\end{abstract}

Keywords: Corneal biomechanics, intraocular pressure, phacoemulsification, trabeculectomy

\section{Introduction}

Corneal viscoelastic properties depend on the corneal collagen fibrils. The arrangement of collagen fibrils varies directionally and regionally, which results in regional

Correspondence: Ronnie George, Medical and Vision Research Foundation, Chennai, India.

E-mail:cgscedis@gmail.com 
differences in elasticity. ${ }^{1,2}$ Hjortdal showed that for a given intraocular pressure (IOP) radially the cornea is stronger at the center and circumferentially at the limbus. It is also known that both corneal and scleral fibrils are fused at the limbus. ${ }^{3}$ Woo et al. found that the corneal biomechanical characteristics are approximately similar to that of the sclera. ${ }^{4}$ The Ocular Response Analyzer (ORA; Reichert Inc., Depew, New York, USA), measures in vivo corneal biomechanical properties such as corneal hysteresis $(\mathrm{CH})$ and corneal resistance factor (CRF) by analyzing corneal responses to indentation by a rapid air pulse. $\mathrm{CH}$ represents the corneal viscoelasticity and has been described as the ability of the tissue to absorb and dissipate energy. CRF represents overall corneal resistance and the ability to withstand the applanation force. ${ }^{5,6}$ Eyes with a higher $\mathrm{CH}$ tend to have increased damping capacity, which buffers the harmful effect of IOP fluctuation on the optic nerve head. Studies have found that eyes with glaucoma have lower $\mathrm{CH}$ compared to normal eyes; this increases the risk for developing glaucomatous optic neuropathy and progression of the disease..$^{7-11}$

Several studies reported the effect of corneal factors on IOP measurements by different tonometers, such as the Goldmann applanation tonometer (GAT), dynamic contour tonometers (DCT), ORA, Tono-Pen, and rebound tonometer (RBT) among normal and glaucoma subjects. It was reported that apart from the technical differences between tonometers, the variability is significantly associated with corneal properties such as central corneal thickness (CCT), corneal radius of curvature (CR), $\mathrm{CH}$, and $\mathrm{CRF} .{ }^{12-18}$ Among all the corneal parameters, the effect of CCT was studied extensively. It is estimated that every ten micron increase in CCT results in $0.35 \mathrm{mmHg}$ difference between GAT and ORA corneal compensated IOP (IOPcC) measurements and $0.80 \mathrm{mmHg}$ between GAT and RBT measurements. ${ }^{18}$

The corneal properties are reported to be altered following refractive and phacoemulsification surgeries due to the incision created in the cornea. ${ }^{19-25}$ In trabeculectomy surgery, a partial scleral flap thickness is created adjacent to the limbus. This may potentially modify the biomechanical properties of the ocular walls. To the best of our knowledge, there are no reports on alterations in corneal biomechanical properties and its effect on IOP measurement following combined phacoemulsification and trabeculectomy (phaco-trab) surgery.

The aim of this study was to evaluate the changes of corneal biomechanical properties and its effect on pre- and postoperative differences in IOP measurement by each tonometer.

\section{Methods and materials}

\section{Study design and subject selection}

This was a single-center observational study. Subjects who underwent phacoemulsification and intraocular lens implantation (phaco-IOL) and subjects who underwent combined phacoemulsification with IOL implantation and trabeculectomy (phaco-trab) during September, 2013 to April, 2014 at a tertiary eye care center, were included in the study. 
The study followed the tenets of the Declaration of Helsinki. The study was approved by the Institutional Review Board of Vision Research Foundation, Chennai, India. Subjects willing to participate in the study were informed in detail about the study and its objectives. Written informed consent was obtained from subjects before enrolling them into the study.

Inclusion criteria for the phaco-IOL group were age more than 30 years, clear cornea with normal fundus, and no previous history of ocular trauma, ocular surgery or refractive surgery. Eyes with any ocular pathology other than cataract were excluded.

Inclusion criteria for the phaco-trab group were age more than 30 years, clear cornea, diagnosed as glaucoma, ${ }^{26}$ and no previous history of ocular trauma, ocular surgery or refractive surgery. Eyes with any other ocular pathology were excluded.

\section{Baseline evaluation}

Subjects underwent a comprehensive ophthalmic examination which included best corrected visual acuity (BCVA), IOP measured by GAT, slit-lamp bio-microscopy, gonioscopy, and stereoscopic dilated fundus evaluation on the slit lamp using a 90D lens. Subjects who had glaucomatous optic disc changes underwent standard automated visual field testing (SAP) (Humphrey Field Analyzer (HFA)) (model 750; Carl Zeiss Meditec). The axial length was measured by using ultrasound biometry (OcuScan ${ }^{\circledast}$ RxP Ophthalmic Ultrasound System, Alcon Laboratories, Inc. South Freeway, Fort Worth, Texas, U.S.A.).

\section{Preoperative assessments}

Preoperative measurements were done one week before the surgery. CR was measured using a keratometer (KMS-6; Appaswamy Associates, Chennai, India) before IOP measurements. IOP was measured using the following tonometers: RBT (Icare; Tiolat Oy, Helsinki, Finland), ORA (Reichert Ophthalmic Instruments, Buffalo, N.Y., U.S.A), Tono-Pen (Tono-Pen XL, Medtronic Solan, Southpoint Drive, North Jacksonville, U.S.A.), DCT (Swiss Microtechnology AG, Port, Switzerland), and GAT (AT-900; Haag Streit AG Gartenstadtstrasse, Koeniz, Switzerland). The RBT and ORA measurements were taken before instillation of topical anaesthesia. Tono-Pen, GAT, and DCT measurement were done after applying anaesthetic eye drops (proparacaine 0.5\%, Paracain; Sunways India Pvt Ltd. Mumbai, India). The order of RBT and ORA measurements were randomized using a simple randomization method. Similarly the order of Tono-Pen, GAT, and DCT measurements were randomized for each subject. CCT was measured using an ultrasonic pachymeter (DGH-550 Pachette 2; DGH technology, Inc., PA, U.S.A.) after five minutes of the last IOP measurement. Repeated measurements were taken until a set of ten values differed by less than ten microns.

\section{IOP measurement protocol}

\section{$R B T$}

RBT was performed in the sitting position without instilling topical anaesthesia. Six measurements were acquired by lightly pressing the tonometer button. The 
instrument automatically averages the six measurements and the mean IOP is displayed. ${ }^{27}$

\section{ORA}

Subjects were asked to place their head against the head rest. Four air puffs within each measurement on each eye were taken; the signal with the highest waveform was automatically selected as the best signal value (BSV) for each eye. Those with poor-quality waveforms (multiple applanation spikes or asymmetric signals) were excluded. IOPcc, IOPg, CH, and CRF were recorded. ${ }^{5}$

\section{Tono-Pen}

The Tono-Pen was calibrated before each measurement. Tono-Pen measurements were taken after anaesthetising the eye. The cornea was applanated with the Tono-Pen tip several times until a reading was displayed. Measurements with a standard error of means (SEM) less than $5 \%$ were included. If successive measurements differed by more than $5 \mathrm{mmHg}$, the procedure were repeated. All Tono-Pen measurements were made with a disposable latex cover over the tip. ${ }^{28}$

\section{GAT}

Calibration for GAT was performed on a daily basis. Topical anaesthesia was instilled and the tear film stained using a sodium fluorescein strip. An average of two measurements was recorded for analysis; if they differed by more than $2.0 \mathrm{mmHg}$, a third reading was taken and the mean of the values was taken for analysis. ${ }^{12}$

\section{$D C T$}

DCT was performed after instilling topical anaesthesia. Each DCT IOP measurement usually requires five to eight seconds where the probe is placed to have continuous contact with the eye. The instrument gives a quality score that ranges from 1 to 5 (lower scores indicate better quality) and Ocular Pulse Amplitude (OPA) value along with IOP measurement. All measurements taken for this study had quality readings ranging from $1-3 .{ }^{29}$

\section{Postoperative measurements}

In addition to routine assessment, pachymetry and IOP were re-evaluated four weeks after performing phaco-IOL surgery and six weeks of phaco-trab using the same devices as mentioned earlier. Both pre- and postoperative $\mathrm{CR}, \mathrm{CH}, \mathrm{CRF}, \mathrm{IOP}$, and CCT measurements were performed by a single observer who was blinded to actual readings and the readings were read and recorded by the second examiner.

\section{Statistical analysis}

The relevant information and test results were recorded in MS Office Excel 2007. Statistical analysis was carried out with SPSS statistical software (Version 14; SPSS Science Inc., Chicago, IL, USA), Med Calc Statistical software version 8.1, and MS-Excel 2007. Only data from the operated eye were considered for statistical analysis. Descriptive statistics were calculated for all parameters of all the groups. Tests for normality were carried out for each continuous variable and appropriate parametric/non-parametric analyses were performed. Type-l error was kept at 5\% 
level. Paired t-test was done to compare between pre- and postoperative measurements. Multiple linear regression was done to find the association between postoperative changes of corneal biomechanics and IOP. No comparison was done between phaco-IOL and phaco-trab group for postoperative measurements.

\section{Results}

Twenty-nine eyes of 29 normal subjects who underwent phaco-IOL and 23 eyes of 23 glaucoma subjects who underwent phaco-trab were included in this study. The mean age of the phaco-IOL and the phaco-trab group was 63.4 years $( \pm 10.6)$ and 65.0 years $( \pm 6.21)$, respectively, and no difference was noted $(p=0.366)$. The mean preoperative $\mathrm{CH}$ was significantly lower and OPA was higher in glaucomatous eyes $(6.97 \pm 2.22 \mathrm{mmHg}$ and $3.04 \pm 1.25 \mathrm{mmHg}$, respectively) as compared to normals $(9.41 \pm 1.67 \mathrm{mmHg}, 1.92 \pm 0.64 \mathrm{mmHg})(p<0.001$; Table 1$)$.

\section{Phaco-IOL group}

Significant increase in CCT [10.48 microns $( \pm 15.04), p=0.001]$ and decrease in $\mathrm{CH}$ $[0.79 \mathrm{mmHg}( \pm 1.39), \mathrm{p}=0.005]$ and $\mathrm{CRF}[1.01 \mathrm{mmHg}( \pm 1.00), \mathrm{p}<0.001]$ were noted post-phaco-IOL surgery. But there was no significant alteration in CR postoperatively $(p=0.094)$. There was no significant difference between pre- and postoperative IOP measured by different tonometers except DCT measurements $[1.15 \mathrm{mmHg}$ ( \pm 2.87$), p=0.039$ ] (Table 1).

\section{Phaco-trab group}

Significant decrease in CCT [16.61 microns $( \pm 15.22), \mathrm{p}<0.001]$ and CRF [2.28 $\mathrm{mmHg}( \pm 1.93), \mathrm{p}<0.001]$ with increase in $\mathrm{CH}[0.95 \mathrm{mmHg},( \pm 1.89), \mathrm{p}=0.026]$ measurements were noted following phaco-trab surgery. There was no alteration in CR followed by phaco-trab surgery, similar to the phaco-IOL group. There was a significant decrease in IOP following phaco-trab surgery measured by all the tonometers $(p<0.001)$. No significant difference was found between pre and post CR measurements in the phaco-trab group $(p=0.43$ ) (Table 1). 


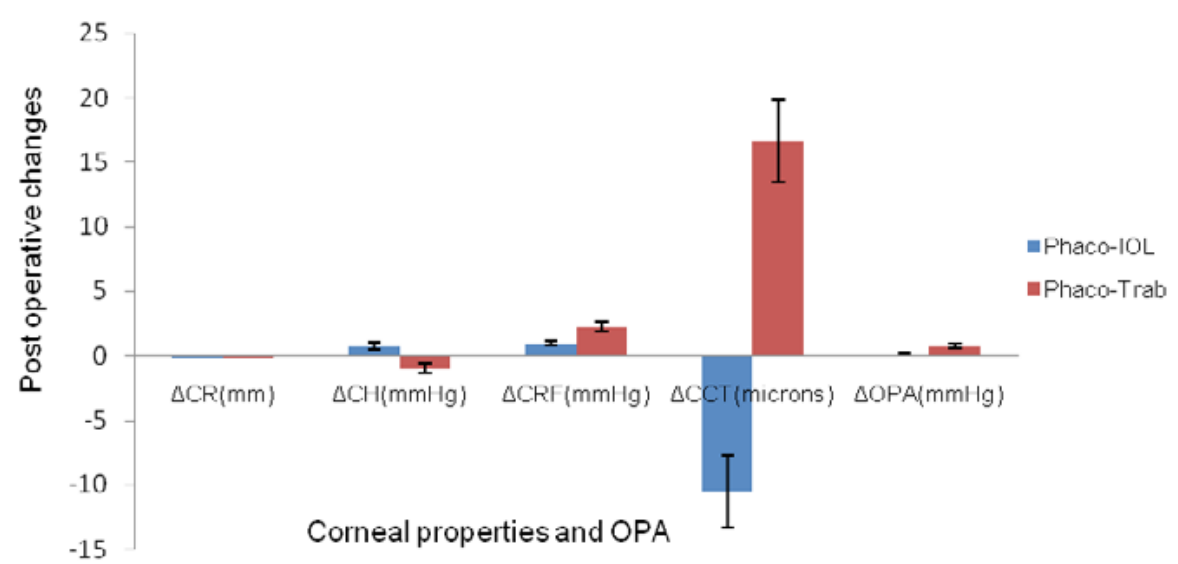

Fig. 1. Postoperative changes of corneal properties and OPA following phaco-IOL and phaco-trab surgeries. $\Delta=$ (preoperative measurements-postoperative measurements); $\mathrm{CH}$ : Corneal hysteresis, CRF: Corneal resistance factor; CR: Average corneal radius of curvature; CCT: Central corneal thickness; $\mathrm{Cl}$ : Confidence interval.

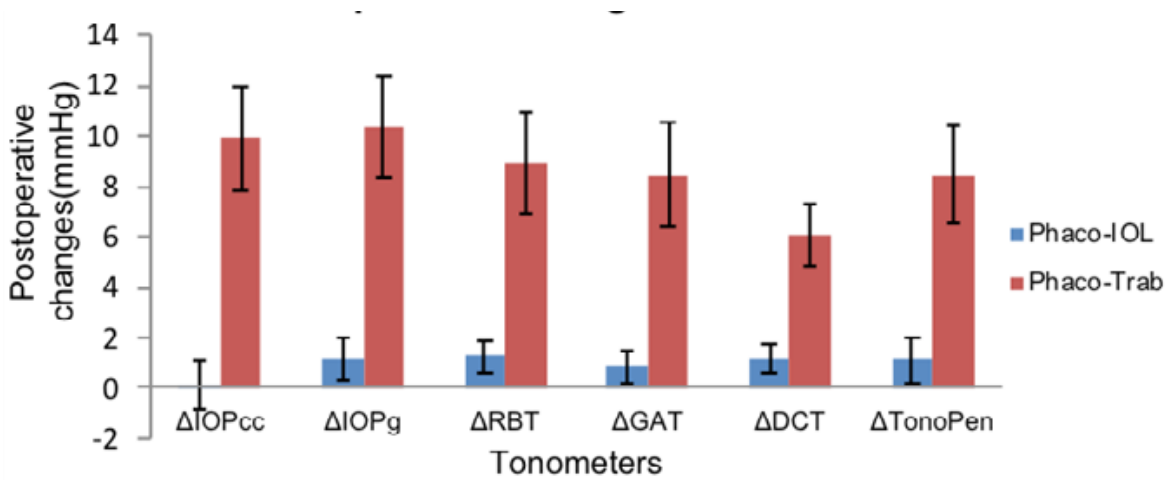

Fig. 2. Postoperative changes of IOP following phaco-IOL and phaco-trab surgeries. $\Delta=$ (preoperative measurements-postoperative measurements); GAT: Goldmann applanation tonometer; IOPcc: Corneal compensated IOP; IOPg: Goldmann correlated IOP; RBT: Rebound tonometer; DCT: Dynamic contour tonometer.

\section{Effect of corneal properties on tonometers}

Simple and multiple linear regression analysis were done with postoperative (phaco-IOL surgery) changes of corneal parameters $(\Delta C R, \Delta C H, \triangle C R F$, and $\triangle C C T)$ as independent factors and $\triangle \mathrm{IOPs}$, i.e., pre- and postoperative (phaco-IOL surgery) difference in IOP measured by different tonometers as dependent variable, which showed $\triangle$ IOPs were significantly associated with $\Delta C H(p<0.001)$ and $\Delta C R F(p<$ 0.001 ) independently among all the corneal parameters. However, $\triangle \mathrm{IOPs}$ measured by each tonometer were not significantly associated with $\Delta C C T(p>0.05)$ and $\Delta C R$ $(p>0.05)$. Similarly, in the phaco-trab group, $\triangle \mathrm{IOPs}$ were significantly associated 
with $\Delta \mathrm{CH}(\mathrm{p}<0.001)$ and $\Delta \mathrm{CRF}(\mathrm{p}<0.001)$ but not with $\Delta \mathrm{CCT}(\mathrm{p}>0.05)$ nor $\Delta \mathrm{CR}(\mathrm{p}$ $>0.05)$ in the regression models.

\section{Effect of axial length on corneal properties and tonometers}

Simple linear regression was done using axial length $(A X L)$ as independent variable and postoperative changes of corneal parameters $(\triangle C R, \triangle C H, \triangle C R F$, and $\triangle C C T)$ and $\triangle \mathrm{IOP}$ measurement by each tonometer as dependent variables. No significant association was found between $A X L$ and postoperative changes of corneal parameters $(p>0.05)$ and postoperative changes in IOP $(p>0.05)$ measured by each tonometer following phaco-IOL and phaco-trab.

\section{Discussion}

Corneal properties were found to be significantly influenced by intraocular surgeries, with which the postoperative changes of IOP measured by each tonometer were explained by the changes of corneal properties.

\section{Phaco-IOL group}

In the phaco-IOL group, we found significant increase in CCT and decrease in $\mathrm{CH}$ and CRF after four weeks after the surgery. Recent studies reported that the decrease in $\mathrm{CH}$ measurement in spite of increased CCT one day after cataract surgery is attributable to corneal edema, which returned to normal values three months after the surgery. ${ }^{22-25}$ In the present study, a significant increase in CCT and decrease in $\mathrm{CH}$ and $\mathrm{CRF}$ were noted even after one month after the surgery. This decrease in $\mathrm{CH}$ and CRF may be due to an incision made on the cornea that could weaken the strength of the eyeball, resulting in lower corneal biomechanics. Lu et al..$^{30}$ reported that there was no significant correlation between soft contact lens-induced corneal edema, $\mathrm{CH}$ and CCT, yet the effect of corneal edema induced by cataract surgery or contact lens on measurements of corneal biomechanics is not clear.

\section{Phaco-trab group}

In the phaco-trab group, we found significant increase in $\mathrm{CH}$ and decrease in $\mathrm{CRF}$ and CCT six weeks after the surgery. This increase in $\mathrm{CH}$ may be explained by the postoperative reduction of IOP. Similar finding were reported by Sun et al. ${ }^{31}$ where IOP was reduced due to anti-glaucoma medications and surgery in subjects with chronic angle closure glaucoma. $\mathrm{CH}$ values significantly increased from $6.83 \pm 2.08$ $\mathrm{mmHg}$ to $9.22 \pm 1.80 \mathrm{mmHg}$ at two weeks and $9.50 \pm 1.66 \mathrm{mmHg}$ at four weeks after treatment. Neuberger et al..$^{32}$ suggested in an experimental study that ORA gives lower $\mathrm{CH}$ measurement in eyes with higher IOP due to limited indentation on the cornea. This reason could probably explain the increased $\mathrm{CH}$ with decreased IOP in post phaco-trab subjects. $\mathrm{CH}$ measurements were dependent on IOP level whereas CRF measurements were not influenced by IOP level. In the present study, we noted that CRF was significantly decreased both post-phaco-IOL and -phacotrab, thereby concluding that the overall resistance of the cornea, i.e., CRF, is altered following intraocular surgeries. 


\section{Postoperative changes in IOP}

A study by Kucumen et al. showed no significant difference pre- and post-1month IOPcc and IOPg measurements following phaco-IOL. ${ }^{22}$ In the present study, we found no significant difference in pre- and postoperative (one month) IOP measurements obtained by all tonometers in the phaco-IOL group except DCT $(p=$ 0.04). Several studies reported that DCT underestimates IOP in eyes with high IOP compared to GAT and overestimates IOP in eyes with low IOP. ${ }^{33,34}$ In the present study, we noted that DCT underestimated IOP $(0.1 \pm 4.4 \mathrm{mmHg}, \mathrm{p}<0.05)$ in preoperative eyes (phaco-trab) as compared to GAT, similar to Tonnu et al. ${ }^{34}$ However, postoperatively (phaco-trab) mean DCT-IOP was $2.2 \mathrm{mmHg}( \pm 2.9)(p>0.05)$ higher than GAT-IOP. Hamilton et al..$^{35}$ and Oh et al. ${ }^{36}$ have also reported that DCT underestimates IOP in eyes with contact lens-induced corneal edema. The reason for this difference in IOP measured by DCT following post-one-month phaco-IOL was not clear. However, the least mean difference was noted $[6.12 \mathrm{mmHg}( \pm 5.85), \mathrm{p}<$ 0.001 ] between pre- and postoperative IOP obtained by DCT following phaco-trab among all the tonometers. In our pilot study, we found that DCT overestimated IOP measurement as compared to GAT in eyes with IOP less than $20 \mathrm{mmHg}$, whereas this pattern reverses in eyes with IOP greater than $20 \mathrm{mmHg}$.

\section{Effect of corneal properties on tonometers}

$\mathrm{CH}$ is significantly lower in glaucomatous eye as compared to non-glaucomatous eyes. Similar findings were noted in the present study. ${ }^{7-9}$ Luce $^{5}$ reported that $\mathrm{CH}$ and CRF are direct measurements of corneal biomechanical properties and more completely describe the effect of corneal biomechanics on IOP measurements than CCT. Hence, we studied the postoperative changes in corneal biomechanics and its effect on IOP measured by all the tonometers.

$C H$ : In the present study, $\triangle \mathrm{CH}$ was negatively associated with $\triangle \mathrm{IOPs}$ both in the phaco-IOL and phaco-trab groups. Multiple linear regression analysis showed postoperative increase in $\mathrm{CH}$ results decrease IOP following phaco-IOL and phaco-trab.

CRF: $\triangle C R F$ was positively associated with $\triangle \mathrm{IOPs}$. Multiple linear regression analysis showed postoperative decrease in CRF results decrease IOP following phaco-IOL and phaco-trab.

Our findings indicate that corneal biomechanics (CH and CRF) independently influenced all tonometers. DCT measurement was less influenced by corneal biomechanics compared to other tonometers. DCT measures IOP by a sensor tip which does not applanate the corneal surface, so theoretically it is not affected by any force-to-pressure translations. The variability between GAT and DCT decreased by $0.7 \mathrm{mmHg}$ for every ten micron increase in CCT. ${ }^{37}$ Doyle et al. ${ }^{38}$ reported that the mean difference between GAT-IOP and DCT-IOP was $-2.6 \mathrm{mmHg}$ in thin corneas and $-0.06 \mathrm{mmHg}$ in thick corneas. According to Kotecha et al. ${ }^{16}$ GAT significantly underestimates IOP compared to DCT and ORA IOPcc in eyes with low CRF, whereas Wang et al. ${ }^{17}$ reported that GAT underestimates IOP compare to DCT eyes with low $\mathrm{CH}$. Those two previous studies did not consider both $\mathrm{CH}$ and $\mathrm{CRF}$ as influential 
factors for IOP measurement. Hence, the variability in IOP measurement among various tonometers can be explained in a better manner by considering all the corneal properties.

In the present study, OPA was significantly higher in glaucomatous eye as compared to non-glaucomatous eyes, which significantly decreased in the phacotrab group but not in the phaco-IOL group. This suggests that OPA is dependent on the level of IOP, a finding similar to that reported by Knecht et al. ${ }^{39}$ In the present study, from the simple and multiple linear regression model we did not find any association between postoperative changes of OPA and $\triangle \mathrm{IOP}$ measured by all tonometers (Table 4). Even after removing OPA from the multiple regression models, we found no difference in the strength of association.

IOP reduction after cataract surgery ranged from 1.3 to $2.05 \mathrm{mmHg}$ at one year follow-up in a few studies. ${ }^{40}$ Issa et al. ${ }^{41}$ reported that the preoperative anterior chamber depth was inversely related to the postoperative IOP reduction, whereas Bhallil et $a l^{42}$ and Huang et $a{ }^{43}$ reported that postoperative IOP reduction was associated with the lens thickness and axial length, not with preoperative and postoperative anterior chamber depth. In the present study we did not find association between axial length and the reduction of IOP following phaco-IOL and phaco-trab. There was also no association between postoperative changes in corneal parameters ( $\triangle \mathrm{CR}, \Delta \mathrm{CH}, \Delta \mathrm{CRF}$, and $\Delta C \mathrm{CT}$ ) with axial length in our study.

This study was done on limited subjects and may not reflect population data. We did not look into the variability of surgeon factor, which could be a confounder of the outcome. Hence, we need quantitative and longitudinal assessment of the corneal biomechanical parameters in eyes that undergo intraocular surgery and its effects on IOP measurements.

\section{Acknowledgement}

We thank Dr Aditya Neog, Consultant, Glaucoma Services, Sankara Nethralaya, for his guidance and support.

\section{References}

1. Aghamohammadzadeh $\mathrm{H}$, Newton $\mathrm{RH}$, Meek KM. X-ray scattering used to map the preferred collagen orientation in the human cornea and limbus. Structure 2004;12(2):249-256.

2. Newton $\mathrm{RH}$, Meek KM. Circumcorneal annulus of collagen fibrils in the human limbus. Invest Ophthalmol Vis Sci 1998;39(7):1125-1134.

3. Hjortdal $\boldsymbol{\varnothing}$. Regional elastic performance of the human cornea. J Biomechanics 1996;29(7):931-942.

4. Woo SY, Kobayashi AS, Schlegel WA, et al. Nonlinear material properties of intact cornea and sclera. Exp Eye Res 1972;14(1):29-39.

5. Luce DA. Determining in vivo biomechanical properties of the cornea with an ocular response analyzer. J Cataract Refract Surg 2005;31(1):156-162.

6. Kotecha A. What biomechanical properties of the cornea are relevant for the clinician? Surv Ophthalmol 2007;52(6):109-114.

7. Mansouri K, Leite MT, Weinreb RN, et al. Association between corneal biomechanical properties and glaucoma severity. Am J Ophthalmol 2012;153(3):419-427. 
Changes in corneal properties and its effect on intraocular pressure measurement following phacoemulsification with intraocular lens implantation with or without trabeculectomy

8. Wells AP, Garway-Heath DF, Poostchi A, et al. Corneal hysteresis but not corneal thickness correlates with optic nerve surface compliance in glaucoma patients. Invest Ophthalmol Vis Sci 2008;49(8):3262-3268.

9. Congdon NG, Broman AT, Bandeen-Roche $K$, et al. Central corneal thickness and corneal hysteresis associated with glaucoma damage. Am J Ophthalmol 2006;141(5):868-875.

10. Kaushik S, Pandav SS, Banger A, et al. Relationship between corneal biomechanical properties, central corneal thickness and intraocular pressure across the spectrum of glaucoma. Am J Ophthalmol 2012;153(5):840-849.

11. Johnson CS, Mian SI, Moroi S, et al. Role of corneal elasticity in damping of intraocular pressure. Invest Ophthalmol Vis Sci 2007;48(6):2540-2544.

12. Whitacre MM, Stein R. Sources of error with use of Goldmann-type tonometers. Surv Ophthalmol 1993;38(1):1-30.

13. Park, SJ, Ang GS, Nicholas S. The effect of thin, thick, and normal corneas on Goldmann intraocular pressure measurements and correction formulae in individual eyes. Ophthalmology 2012;119(3):443-449.

14. Bhan A, Browning AC, Shah S, et al. Effect of corneal thickness on intraocular pressure measurements with the pneumotonometer, Goldmann applanation tonometer, and Tono-Pen. Invest Ophthalmol Vis Sci 2002;43(5):1389-1392.

15. Gunvant P, Baskaran M, Vijaya L et al. Effect of corneal parameters on measurements using the pulsatile ocular blood flow tonograph and Goldmann applanation tonometer. $\mathrm{Br} J$ Ophthalmol 2004;88(4):518-522.

16. Kotecha A, White $E$, Schlottmann PG, et al. Intraocular pressure measurement precision with the Goldmann applanation, dynamic contour, and ocular response analyzer tonometers. Ophthalmology 2010;117(4):730-737.

17. Wang J, Cayer MM, Descovich D, et al. Assessment of factors affecting the difference in intraocular pressure measurements between dynamic contour tonometry and Goldmann applanation tonometry. J Glaucoma 2011;20(8):482-487.

18. Ouyang PB, Li CY, Zhu XH, et al. Assessment of intraocular pressure measured by Reichert ocular response analyzer, Goldmann applanation tonometry, and dynamic contour tonometry in healthy individuals. Int J Ophthalmol 2012;5(1):102-107.

19. Pepose JS, Feigenbaum SK, Qazi MA, et al. Changes in corneal biomechanics and intraocular pressure following LASIK using static, dynamic and noncontact tonometry. Am J Ophthalmol 2007;143(1):39-47.

20. Shemesh G, Soiberman U, Kurtz S. Intraocular pressure measurements with Goldmann applanation tonometry and dynamic contour tonometry in eyes after Intra LASIK or LASEK. ClinOphthalmol 2011;6:1967-1970.

21. Kucumen RB, Yenerel NM, Gorgun E, et al. Corneal biomechanical properties and intraocular pressure changes after phacoemulsification and intraocular lens implantation. J Cataract Refract Surg 2008;34(12):2096-2098.

22. de Freitas VB, Ventura MP, da Silva RS, et al. Central corneal thickness and biomechanical changes after clear corneal phacoemulsification. J Refract Surg 2012;28(3):215-219.

23. Alió JL, Agdeppa MCC, Rodríguez-Prats JL, et al. Factors influencing corneal biomechanical changes after micro-incision cataract surgery and standard coaxial phacoemulsification. J Cataract Refract Surg 2010;36(6):890-897.

24. Kamiya K, Shimizu K, Ohmoto F, et al. Time course of corneal biomechanical parameters after phacoemulsification with intraocular lens implantation. Cornea 2010;29(11):1256-1260.

25. Hager A, Loge K, Füllhas MO, et al. Changes in corneal hysteresis after clear corneal cataract surgery. Am J Ophthalmol 2007;144(3):341-346.

26. Foster PJ, Buhrmann R, Quigley HA, et al. The definition and classification of glaucoma in prevalence surveys. Br J Ophthalmol 2002;86(2):238-242.

27. Kontiola Al. A new induction based impact method for measuring intraocular pressure. Acta Ophthalmol. Scand 2000;78(2):142-145.

28. Hessemer V, Rössler R, Jacobi, KW. Tono-Pen, a new position-independent tonometer Comparison with the Goldmann tonometer by applanation measurement. Klin Monatsbl Augenheilkd 1988;193(4):420-426. 
29. Kanngiesser $\mathrm{HE}$, Kniestedt $\mathrm{C}$, Robert $\mathrm{YC}$. Dynamic contour tonometry: presentation of a new tonometer. J Glaucoma 2005;14(5):344-350

30. Lu F, Xu S, Qu J, et al. Central corneal thickness and corneal hysteresis during corneal swelling induced by contact lens wear with eye closure. Am J Ophthalmol 2007;143(4):616-622.

31. Sun $L$, Shen $M$, Wang J, et al. Recovery of corneal hysteresis after reduction of intraocular pressure in chronic primary angle-closure glaucoma. Am J Ophthalmol 2009;147(6):1061-1066.

32. Neuburger $M$, Böhringer $D$, Reinhard $T$, et al. Recovery of corneal hysteresis after reduction of intraocular pressure in chronic primary angle-closure glaucoma. Am J Ophthalmol 2010;149(4):687-688.

33. Francis BA, Hsieh A, Lai MY, et al. Effects of corneal thickness, corneal curvature, and intraocular pressure level on Goldmann applanation tonometry and dynamic contour tonometry. Ophthalmology 2007;114(1):20-26.

34. Tonnu PA, Ho T, Sharma K, et al. A comparison of four methods of tonometry: method agreement and interobserver variability. Br J Ophthalmol 2005;89(7):847-850.

35. Hamilton KE, Pye DC, Kao L, et al. The effect of corneal edema on dynamic contour and Goldmann tonometry. Optom Vis Sci 2008;8(6)5:451-456.

36. Oh JH, Yoo C, Kim YY, et al. The effect of contact lens-induced corneal edema on Goldmann applanation tonometry and dynamic contour tonometry. Graefes Arch Clin Exp Ophthalmol 2009;247(3):371-375.

37. Ceruti P, Morbio R, MarraffaM, Marchini G. Comparison of Goldmann applanation tonometry and dynamic contour tonometry in healthy and glaucomatous eyes. Eye 2009;23(2):262-269.

38. Doyle A, Lachkar Y. Comparison of dynamic contour tonometry with Goldman applanation tonometry over a wide range of central corneal thickness. J Glaucoma 2005;14(4):288-292.

39. Knecht PB, Bosch MM, Michels S, et al. The ocular pulse amplitude at different intraocular pressure: a prospective study. Acta ophthalmologica 2011;89(5):e466-e471.

40. Guan $\mathrm{H}$, Mick A, Porco T, et al. Preoperative factors associated with IOP reduction after cataract surgery. Optom Vis Sci 2013;90(2):179-184.

41. Issa SA, Pacheco J, Mahmood U, et al. A novel index for predicting intraocular pressure reduction following cataract surgery. Br J Ophthalmol 2005;89(5):543-546.

42. Bhallil S, Andalloussi IB, Chraibi F, et al. Changes in intraocular pressure after clear corneal phacoemulsification in normal patients. Oman J Ophthalmol 2009;2(3):111-113.

43. Huang G, Gonzalez E, Peng PH, et al. Anterior chamber depth, iridocorneal angle width and intraocular pressure changes after phacoemulsification: narrow vs open iridocorneal angles. Arch Ophthalmol 2011;129(10):1283-1290. 


\section{Tables}

Table 1. Pre- and postoperative changes in corneal biomechanical properties and IOP measured by different tonometers.

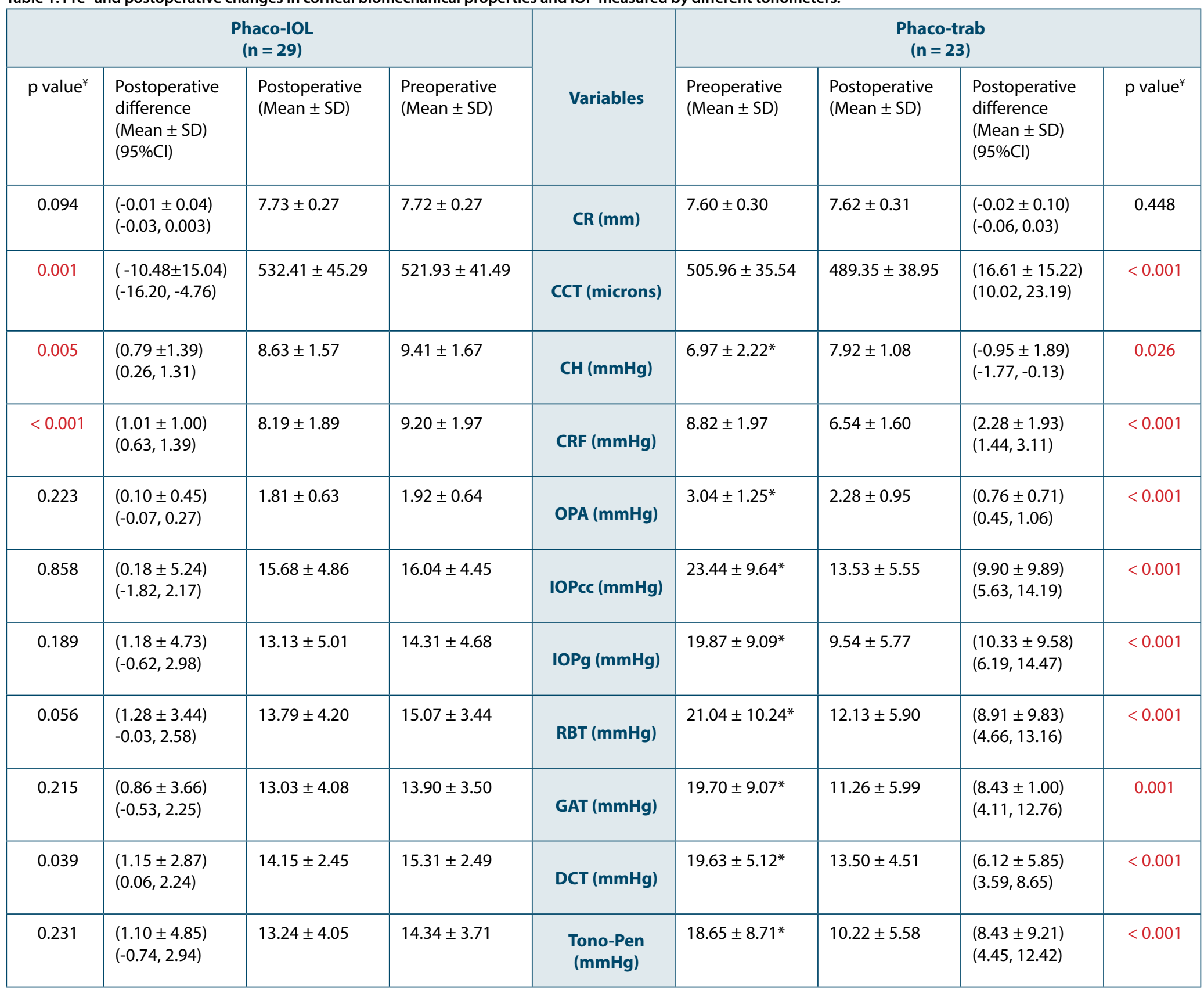

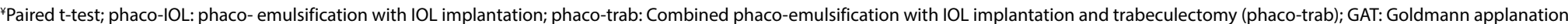

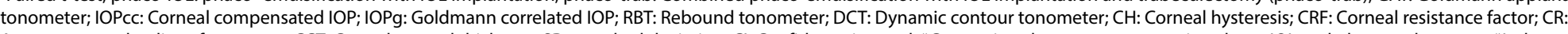

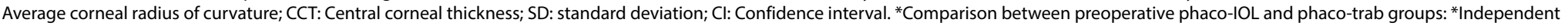
$\mathrm{t}$-test; significant level $\mathrm{p}<0.05$. 
Table 2. Simple linear regression on changes of corneal properties and changes in IOP measurements by each tonometer, following phaco-IOL.

\begin{tabular}{|c|c|c|c|c|c|c|}
\hline$\frac{0}{8}$ & $\begin{array}{l}\text { Independent } \\
\text { variables }\end{array}$ & $\Delta C R$ & $\Delta \mathrm{CH}$ & $\Delta C R F$ & $\triangle \mathrm{CCT}$ & $\triangle O P A$ \\
\hline \multirow{5}{*}{$\begin{array}{l}\text { U } \\
\frac{0}{0}\end{array}$} & $\mathrm{R}^{2}$ & 0.003 & 0.706 & 0.165 & 0.000 & 0.012 \\
\hline & Constant & 0.263 & 2.663 & -1.969 & 0.160 & 0.045 \\
\hline & beta & 5.975 & -3.164 & 2.130 & -0.002 & 1.265 \\
\hline & $95 \% \mathrm{Cl}$ & -39.565 to 51.515 & -3.969 to -2.358 & 0.240 to 4.021 & -0.139 to 0.136 & -3.336 to 5.867 \\
\hline & p value & 0.790 & $<0.001$ & 0.029 & 0.982 & 0.577 \\
\hline \multirow{5}{*}{$\frac{0}{0}$} & $\mathrm{R}^{2}$ & 0.002 & 0.513 & 0.336 & 0.002 & 0.023 \\
\hline & Constant & 1.244 & 3.100 & -1.581 & 1.028 & 1.017 \\
\hline & beta & 4.226 & -2.438 & 2.745 & -0.015 & 1.603 \\
\hline & $95 \% \mathrm{Cl}$ & -36.970 to 45.421 & -3.376 to -1.501 & 1.220 to 4.269 & -0.139 to 0.109 & -2.534 to 5.740 \\
\hline & p value & 0.835 & $<0.001$ & 0.001 & 0.809 & 0.433 \\
\hline \multirow{5}{*}{ 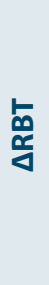 } & $\mathrm{R}^{2}$ & 0.002 & 0.448 & 0.193 & 0.002 & 0.002 \\
\hline & Constant & 1.320 & 2.578 & -0.248 & 1.178 & 1.245 \\
\hline & beta & 3.033 & -1.656 & 1.513 & -0.009 & 0.299 \\
\hline & $95 \% \mathrm{Cl}$ & -26.914 to 32.981 & -2.382 to -0.931 & 0.292 to 2.737 & -0.100 to 0.081 & -2.741 to 3.339 \\
\hline & p value & 0.837 & $<0.001$ & 0.017 & 0.834 & 0.841 \\
\hline \multirow{5}{*}{ 昼 } & $\mathrm{R}^{2}$ & 0.002 & 0.360 & 0.292 & 0.001 & 0.003 \\
\hline & Constant & 0.814 & 2.103 & -1.133 & 0.783 & 0.817 \\
\hline & beta & -3.304 & -1.578 & 1.981 & -0.008 & 0.432 \\
\hline & $95 \% \mathrm{Cl}$ & -35.160 to 28.552 & -2.410 to -0.747 & 0.764 to 3.198 & -0.104 to 0.089 & -2.800 to 3.664 \\
\hline & p value & 0.833 & 0.001 & 0.002 & 0.873 & 0.786 \\
\hline \multirow{5}{*}{ 它 } & $\mathrm{R}^{2}$ & 0.007 & 0.472 & 0.122 & 0.021 & 0.059 \\
\hline & Constant & 1.078 & 2.267 & 0.149 & 0.866 & 0.994 \\
\hline & beta & -5.313 & -1.415 & 1.000 & -0.028 & 1.557 \\
\hline & $95 \% \mathrm{Cl}$ & -30.179 to 19.554 & -2.006 to -0.824 & -0.061 to 2.061 & -0.102 to 0.047 & -0.900 to 4.015 \\
\hline & $\mathrm{p}$ value & 0.665 & $<0.001$ & 0.064 & 0.454 & 0.204 \\
\hline \multirow{5}{*}{$\begin{array}{l}\frac{5}{0} \\
0 \\
\frac{0}{0} \\
\frac{c}{0} \\
\frac{0}{4}\end{array}$} & $\mathrm{R}^{2}$ & 0.002 & 0.419 & 0.192 & 0.001 & 0.000 \\
\hline & Constant & 1.178 & 2.878 & -1.037 & 0.985 & 1.105 \\
\hline & beta & 5.085 & -2.257 & 2.126 & -0.011 & -0.020 \\
\hline & $95 \% \mathrm{Cl}$ & -37.096 to 47.267 & -3.306 to -1.208 & 0.404 to 3.848 & -0.139 to 0.116 & -4.306 to 4.267 \\
\hline & $p$ value & 0.806 & $<0.001$ & 0.017 & 0.857 & 0.993 \\
\hline
\end{tabular}


Table 3. Multiple linear regression on changes of corneal properties and changes in IOP measurements by each tonometer, following phaco-IOL.

\begin{tabular}{|c|c|c|c|c|c|}
\hline$\frac{0}{4}$ & $\begin{array}{c}\text { Independent } \\
\text { variables }\end{array}$ & $\Delta C R$ & $\Delta \mathrm{CH}$ & $\Delta C R F$ & $\triangle \mathrm{CCT}$ \\
\hline \multirow{5}{*}{$\begin{array}{l}\text { पू } \\
\text { ơ } \\
\frac{0}{4}\end{array}$} & $\mathrm{R} 2$ & \multicolumn{4}{|l|}{0.998} \\
\hline & Constant & \multicolumn{4}{|l|}{0.022} \\
\hline & beta & -1.085 & -3.477 & 2.866 & 0.001 \\
\hline & $95 \% \mathrm{Cl}$ & -3.094 to 0.925 & -3.543 to -3.411 & 2.774 to 2.959 & -0.005 to 0.008 \\
\hline & $p$ value & 0.276 & $<0.001$ & $<0.001$ & 0.643 \\
\hline \multirow{5}{*}{$\begin{array}{l}\text { 임 } \\
\frac{0}{4}\end{array}$} & $\mathrm{R} 2$ & \multicolumn{4}{|l|}{0.998} \\
\hline & Constant & \multicolumn{4}{|l|}{0.033} \\
\hline & beta & -0.616 & -2.801 & 3.341 & 0.002 \\
\hline & $95 \% \mathrm{Cl}$ & -2.689 to 1.457 & -2.869 to -2.734 & 3.245 to 3.436 & -0.004 to 0.008 \\
\hline & $\mathrm{p}$ value & 0.546 & $<0.001$ & $<0.001$ & 0.532 \\
\hline \multirow{5}{*}{$\begin{array}{l}\text { 吕 } \\
\text { 宅 }\end{array}$} & $\mathrm{R} 2$ & \multicolumn{4}{|l|}{0.748} \\
\hline & Constant & \multicolumn{4}{|l|}{0.799} \\
\hline & beta & -0.250 & -1.867 & 1.898 & -0.003 \\
\hline & $95 \% \mathrm{Cl}$ & -16.567 to 16.067 & $-2.400)$ to -1.334 & 1.146 to 2.649 & -0.053 to 0.047 \\
\hline & $\mathrm{p}$ value & 0.975 & $<0.001$ & $<0.001$ & 0.907 \\
\hline \multirow{5}{*}{ 方 } & $\mathrm{R} 2$ & \multicolumn{4}{|l|}{0.775} \\
\hline & Constant & \multicolumn{4}{|l|}{-0.093} \\
\hline & beta & -6.763 & -1.846 & 2.388 & 0.009 \\
\hline & $95 \% \mathrm{Cl}$ & -23.147 to 9.620 & -2.381 to -1.311 & 1.633 to 3.142 & -0.041 to 0.060 \\
\hline & $\mathrm{p}$ value & 0.403 & $<0.001$ & $<0.001$ & 0.710 \\
\hline \multirow{5}{*}{ 七̌ } & $\mathrm{R} 2$ & \multicolumn{4}{|l|}{0.714} \\
\hline & Constant & \multicolumn{4}{|l|}{0.801} \\
\hline & beta & -7.296 & -1.602 & 1.249 & -0.024 \\
\hline & $95 \% \mathrm{Cl}$ & -21.768 to 7.177 & -2.075 to -1.129 & 0.582 to 1.916 & -0.068 to 0.021 \\
\hline & $p$ value & 0.309 & $<0.001$ & 0.001 & 0.281 \\
\hline \multirow{5}{*}{ 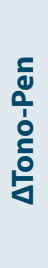 } & $\mathrm{R} 2$ & \multicolumn{4}{|l|}{0.714} \\
\hline & Constant & \multicolumn{4}{|l|}{0.417} \\
\hline & beta & 0.559 & -2.547 & 2.658 & -0.002 \\
\hline & $95 \% \mathrm{Cl}$ & -23.942 to 25.061 & -3.347 to -1.747 & 1.529 to 3.787 & -0.078 to 0.074 \\
\hline & $p$ value & 0.963 & $<0.001$ & $<0.001$ & 0.957 \\
\hline
\end{tabular}

${ }^{*} \Delta=$ (preoperative measurements-postoperative measurements); GAT: Goldmann applanation tonometer; IOPcc: Corneal compensated IOP; IOPg: Goldmann correlated IOP; RBT: Rebound tonometer; DCT: Dynamic contour tonometer; $\mathrm{CH}$ : Corneal hysteresis; CRF: Corneal resistance factor; CR: Average corneal radius of curvature; CCT: Central corneal thickness Cl: Confidence interval. 
Table 4. Simple linear regression on changes of corneal properties and changes in IOP measurements by each tonometer, following phaco-trab.

\begin{tabular}{|c|c|c|c|c|c|c|}
\hline$\frac{0}{4}$ & $\begin{array}{c}\text { Independent } \\
\text { variables }\end{array}$ & $\Delta \mathrm{CR}$ & $\Delta \mathrm{CH}$ & $\Delta$ CRF & $\triangle \mathrm{CCT}$ & $\triangle O P A$ \\
\hline \multirow{5}{*}{$\begin{array}{l}\text { U. } \\
\text { 음 }\end{array}$} & $\mathrm{R} 2$ & 0.048 & 0.709 & 0.546 & 0.065 & 0.043 \\
\hline & Constant & 9.558 & 5.747 & 1.294 & 7.154 & 7.725 \\
\hline & beta & -21.623 & -4.390 & 3.781 & 0.166 & 2.887 \\
\hline & $95 \% \mathrm{Cl}$ & -65.177 to 21.931 & -5.666 to -3.115 & 2.218 to 5.345 & -0.119 to 0.451 & -3.292 to 9.066 \\
\hline & $p$ value & 0.314 & $<0.001$ & $<0.001$ & 0.240 & 0.342 \\
\hline \multirow{5}{*}{$\begin{array}{l}\text { ㅇ } \\
\frac{0}{4}\end{array}$} & $\mathrm{R} 2$ & 0.058 & 0.583 & 0.675 & 0.056 & 0.037 \\
\hline & Constant & 9.959 & 6.677 & 1.057 & 7.863 & 8.372 \\
\hline & beta & -22.894 & -3.854 & 4.070 & 0.149 & 2.588 \\
\hline & $95 \% \mathrm{Cl}$ & -64.866 to 19.079 & -5.334 to -2.375 & 2.788 to 5.352 & -0.129 to 0.426 & -3.415 to 8.592 \\
\hline & $\mathrm{p}$ value & 0.269 & $<0.001$ & $<0.001$ & 0.278 & 0.380 \\
\hline \multirow{5}{*}{$\begin{array}{l}\text { 品 } \\
\text { 安 }\end{array}$} & $\mathrm{R} 2$ & 0.060 & 0.708 & 0.396 & 0.020 & 0.083 \\
\hline & Constant & 8.525 & 4.783 & 1.628 & 7.385 & 5.891 \\
\hline & beta & -23.929 & -4.358 & 3.198 & 0.092 & 3.995 \\
\hline & $95 \% \mathrm{Cl}$ & -66.937 to 19.079 & -5.628 to -3.088 & 1.405 to 4.990 & -0.198 to 0.382 & -2.013 to 10.003 \\
\hline & $\mathrm{p}$ value & 0.260 & $<0.001$ & 0.001 & 0.517 & 0.181 \\
\hline \multirow{5}{*}{ 昶 } & R2 & 0.068 & 0.589 & 0.762 & 0.044 & 0.028 \\
\hline & Constant & 8.014 & 4.604 & -0.540 & 6.137 & 6.643 \\
\hline & beta & -25.945 & -4.042 & 3.939 & 0.138 & 2.369 \\
\hline & $95 \% \mathrm{Cl}$ & -69.503 to 17.613 & -5.575 to -2.508 & 2.420 to 5.459 & -0.153 to 0.430 & -3.923 to 8.661 \\
\hline & $p$ value & 0.229 & $<0.001$ & $<0.001$ & 0.334 & 0.442 \\
\hline \multirow{5}{*}{ 旨 } & $\mathrm{R} 2$ & 0.031 & 0.600 & 0.495 & 0.022 & 0.065 \\
\hline & Constant & 5.957 & 3.858 & 1.273 & 5.173 & 4.530 \\
\hline & beta & -10.171 & -2.389 & 2.128 & 0.057 & 2.104 \\
\hline & $95 \% \mathrm{Cl}$ & -36.169 to 15.828 & -3.273 to -1.505 & 1.153 to 3.104 & -0.115 to 0.230 & -1.507 to 5.716 \\
\hline & $\mathrm{p}$ value & 0.425 & $<0.001$ & $<0.001$ & 0.498 & 0.239 \\
\hline \multirow{5}{*}{ 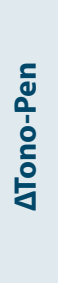 } & $\mathrm{R} 2$ & 0.048 & 0.048 & 0.671 & 0.047 & 0.075 \\
\hline & Constant & 8.110 & 5.245 & -0.457 & 6.251 & 5.744 \\
\hline & beta & -20.021 & -3.365 & 3.903 & 0.132 & 3.556 \\
\hline & $95 \% \mathrm{Cl}$ & -60.616 to 20.574 & -4.955 to -1.776 & 2.662 to 5.145 & -0.137 to 0.400 & -2.103 to 9.216 \\
\hline & $p$ value & 0.317 & $<0.001$ & $<0.001$ & 0.319 & 0.205 \\
\hline
\end{tabular}


Table 5. Multiple linear regression on changes of corneal properties and changes in IOP measurements by each tonometer, following phaco-trab.

\begin{tabular}{|c|c|c|c|c|c|}
\hline 은 & Independent variables & $\Delta C R$ & $\Delta \mathrm{CH}$ & $\Delta C R F$ & $\Delta \mathrm{CCT}$ \\
\hline \multirow{5}{*}{$\begin{array}{l}\text { Ŭ } \\
\text { 음 }\end{array}$} & $\mathrm{R} 2$ & \multicolumn{4}{|l|}{0.999} \\
\hline & Constant & \multicolumn{4}{|l|}{-0.043} \\
\hline & beta & -1.487 & -3.623 & 2.831 & 0.003 \\
\hline & $95 \% \mathrm{Cl}$ & -3.197 to 0.222 & -3.717 to -3.529 & 2.740 to 2.923 & -0.009 to 0.014 \\
\hline & $\mathrm{p}$ value & 0.084 & $<0.001$ & $<0.001$ & 0.636 \\
\hline \multirow{5}{*}{$\begin{array}{l}\frac{0}{4} \\
\frac{0}{4}\end{array}$} & $\mathrm{R} 2$ & \multicolumn{4}{|l|}{0.999} \\
\hline & Constant & \multicolumn{4}{|l|}{-0.030} \\
\hline & beta & -1.842 & -2.965 & 3.284 & 0.002 \\
\hline & $95 \% \mathrm{Cl}$ & -3.668 to -0.015 & -3.066 to -2.865 & 3.187 to 3.382 & -0.010 to 0.014 \\
\hline & $p$ value & 0.050 & $<0.001$ & $<0.001$ & 0.702 \\
\hline \multirow{5}{*}{$\begin{array}{l}\stackrel{5}{\infty} \\
\stackrel{c}{q}\end{array}$} & $\mathrm{R} 2$ & \multicolumn{4}{|l|}{0.904} \\
\hline & Constant & \multicolumn{4}{|l|}{1.352} \\
\hline & beta & -6.235 & -3.908 & 2.175 & -0.072 \\
\hline & $95 \% \mathrm{Cl}$ & -21.751 to 9.280 & -4.763 to -3.053 & 1.343 to 3.006 & -0.176 to 0.031 \\
\hline & $p$ value & 0.410 & $<0.001$ & $<0.001$ & 0.160 \\
\hline \multirow{5}{*}{ 求 } & $\mathrm{R} 2$ & \multicolumn{4}{|l|}{0.930} \\
\hline & Constant & \multicolumn{4}{|l|}{-1.440} \\
\hline & beta & -5.466 & -3.231 & 3.052 & -0.014 \\
\hline & $95 \% \mathrm{Cl}$ & -18.898 to 7.965 & -3.971 to -2.491 & 2.333 to 3.772 & -0.103 to 0.076 \\
\hline & $\mathrm{p}$ value & 0.404 & $<0.001$ & $<0.001$ & 0.749 \\
\hline \multirow{5}{*}{ 七 } & $\mathrm{R} 2$ & \multicolumn{4}{|l|}{0.878} \\
\hline & Constant & \multicolumn{4}{|l|}{1.038} \\
\hline & beta & 1.511 & -2.036 & 1.655 & -0.036 \\
\hline & $95 \% \mathrm{Cl}$ & -8.882 to 11.903 & -2.609 to -1.463 & 1.098 to 2.212 & -0.105 to 0.034 \\
\hline & $p$ value & 0.764 & $<0.001$ & $<0.001$ & 0.294 \\
\hline \multirow{5}{*}{ 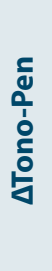 } & $\mathrm{R} 2$ & \multicolumn{4}{|l|}{0.917} \\
\hline & Constant & \multicolumn{4}{|l|}{-1.390} \\
\hline & beta & 0.049 & -2.493 & 3.263 & 0.002 \\
\hline & $95 \% \mathrm{Cl}$ & -13.490 to 13.588 & -3.239 to -1.747 & 2.537 to 3.989 & -0.088 to 0.092 \\
\hline & $p$ value & 0.994 & $<0.001$ & $<0.001$ & 0.968 \\
\hline
\end{tabular}

${ }^{*} \Delta=$ (Preoperative measurements- Postoperative measurements); GAT: Goldmann applanation tonometer; IOPcc: Corneal compensated IOP; IOPg: Goldmann correlated IOP; RBT: Rebound tonometer; DCT: Dynamic contour tonometer; $\mathrm{CH}$ : Corneal hysteresis; CRF: Corneal resistance factor; CR: Average corneal radius of curvature; CCT: Central corneal thickness Cl: Confidence interval. 